\title{
Liderando transições: a arte dos campeões
}

Bom-dia a todos. Estou contente de estar aqui hoje para compartilhar algumas de minhas idéias sobre mudança e liderança. Estou hoje em sua frente também me sentindo bastante pequeno. Por quê? Tenho certeza que muitos de vocês, no auditório, poderiam estar aqui falando, nesta manhã, com base nas suas experiências, no trabalho que vocês fazem, nos estudos que vocês fizeram ou talvez ainda estejam fazendo. Eu não me sinto tão pequeno a ponto de não reconhecer meu trabalho, minha paixão em ajudar os outros a desenvolverem liderança. Para mim tem sido uma jornada de quase 40 anos. Portanto, eu me orgulho de estar aqui hoje para compartilhar alguns pensamentos, muitas vezes extraídos do trabalho de outros, mas que refletem a filosofia que mantenho sobre liderança e sobre as transições pelas quais as pessoas têm de passar durante mudanças, em particular mudanças significativas.

É um privilégio estar aqui nesta Escola Nacional de Saúde Pública. Creio que uma porção de vocês está fazendo estudos avançados em nível de mestrado e doutorado na questão de saúde pública. Os desafios que vocês enfrentam nessa área tão importante são tremendos. A necessidade de liderança forte e compassiva é enorme. A quantidade de mudança pela qual vocês estão passando e a necessidade de encarar continuamente suas próprias transições valem a pena serem notadas.

Eu tive o privilégio de conhecer, no ano passado, alguns de seus conterrâneos. Vários deles participaram de nosso programa de liderança na Escola de Serviço Público do Canadá, e eu apreciei as contribuições deles para a investigação que fizemos juntos sobre liderança. Mas essa é a primeira oportunidade que tive de visitar seu belo país e de passar um tempo respirando sua cultura e adquirindo, pelo menos, um pouco de

John Flynn é pós-graduado em Teologia pela Universidade de St. Paul (EUA) e Consultor em Mudanças Organizacionais e Desenvolvimento de Lideranças da Canada School of Public Service.

Contato: john.flynn@ csps-efpc.gc.ca 
conhecimento sobre essa cultura. Eu saúdo vocês e agradeço por me receberem e passarem algum tempo comigo e com minhas idéias.

Aqui no Brasil, como em todo lugar do mundo, está acontecendo muita mudança. O governo de vocês, apoiado pelo seu serviço público, está lutando para garantir que essa mudança seja na direção certa, do povo do Brasil. Para mim esse plano é bastante nobre e requer de muitos uma capacidade de liderança essencial para o sucesso de vocês.

D. H. Lawrence uma vez escreveu: "O mundo tem mais medo de uma experiência nova do que qualquer outra coisa, porque uma experiência nova desloca tantas experiências antigas. O mundo não tem medo de uma idéia nova. Ele consegue classificar qualquer idéia. Mas ele não consegue classificar uma experiência realmente nova”.

Mudança é uma experiência realmente nova. Todos nós conhecemos mudança. Muitas vezes nos dizem: "A mudança veio para ficar" ou "A única coisa constante é a mudança". Nós sabemos que esses clichês refletem a realidade, mas eles não falam toda a verdade. Para mim, e acredito que para alguns de vocês, a mudança nem sempre é confortável. Especialmente depois que eu alcanço uma posição boa em que tudo vai bem, começo a pensar “a vida é boa. Que a vida sempre seja!” De repente, bum! Algo acontece e aquela zona de conforto desaparece. Acontece que todas as mudanças pelas quais já passei tenho me saído como uma pessoa que gosta de mudanças, e freqüentes. Então, tenho de me perguntar o que acontece comigo ou com você, quando temos essas reações.

Cada um de nós tem, pelo menos, uma história significante para contar sobre mudanças dramáticas e, talvez, dolorosas em nossas vidas; o tipo de mudança que nós vivenciamos nos faz ver o mundo de maneira diferente, com lentes novas. Geralmente esse tipo de mudança acontece quando nós já estamos bem adultos, mas, talvez, para alguns essa mudança ocorreu quando éramos mais novos.

Muitos de nós já experimentamos mudanças mais alegres, que nos pode ter surpreendido, mas as conseqüências foram bastante positivas. Em situações como essas, a "mudança" torna-se nossa amiga, uma aliada.

Quando nós somos confrontados com mudanças em nossas vidas, às vezes fazemos um jogo de cintura e nos adaptamos até facilmente, ou resistimos à mudança, vendo-a como desnecessária e intrusiva. Às vezes nós nos surpreendemos com a força da nossa reação a mudanças. Quando analisamos essa reação, descobrimos que desenvolvemos muitas respostas defensivas. Eu me oponho, porque a mudança é desnecessária, ou boba, ou não vai funcionar.

William Bridges escreveu um livro chamado Lidando com transições com o subtítulo Tirando o máximo de proveito de uma mudança. No parágrafo inicial ele escreve: 
"Não são as mudanças que acabam com você, são as transições. Mudança não é o mesmo que transição. Mudança envolve situação: o novo local, o novo chefe, as novas funções na equipe, as novas políticas. Transição é o processo psicológico pelo qual as pessoas passam para se entenderem com a nova situação. Mudança é algo externo, transição é interno".

Então, decidi dar o seguinte título a esta palestra: "Liderando transições: a arte dos campeões", que quer dizer que eu decidi olhar a resposta humana a mudanças, o que acontece "dentro" de mim; "dentro" de você, quando nos confrontamos com a mudança. Muitas vezes precisamos de ajuda para trabalhar com a mudança. Podemos refletir sobre o que está acontecendo conversando com um amigo querido e sincero, com um conselheiro ou com um mentor, mas cada um de nós, no final, tem de passar pela própria transição causada por essa mudança.

Em seu livro, Bridges fala sobre a importância e as dificuldades de novos começos, os começos que são disparados pelas mudanças fora de nós. Começos, diz ele, são realmente assustadores para muitos de nós, e ele dá quatro razões para isso.

1) Começos trazem de volta preocupações antigas sobre o que aconteceu em começos passados e, talvez, algum desses começos passados não foi dos melhores.

2) Quando iniciamos novos começos, percebemos que estamos numa área de alto risco. Será mesmo que damos conta disso? Será que temos as habilidades e a experiência necessárias para esse novo começo?

3) Bridges nos fala que arriscar nos faz lembrar de fracassos anteriores que podemos ter tido em outros novos começos, e esses fracassos bem podem ter sido traumáticos.

4) A maior parte das pessoas geralmente sente-se confortável no que Bridges chama de zona neutra: o lugar onde estamos imediatamente antes desse novo começo. Deixar o conforto da zona neutra pode ser bastante desnorteante.

Tentar entender a nós mesmos e nossas reações é traiçoeiro. Leva tempo e precisamos refletir sobre nossas reações emocionais. É difícil sermos objetivos e vermos a nós mesmos com olhos diferentes.

Nas minhas experiências de vida, acho que minha transição através de mudanças é mais difícil quando eu não sou o autor da mudança, quando a mudança me é imposta. Eu acredito que seja o mesmo para vocês. E isso pode acontecer em vários lugares: em sua família, em sua comunidade, numa organização voluntária a que você pertence e certamente pode acontecer no seu trabalho.

No trabalho é difícil. Por quê? Porque nós passamos uma parte significativa de nossas vidas lá e porque nós temos orgulho do que fazemos, 
importamos-nos com o que fazemos e, pelo menos em parte, o trabalho ajuda a definir quem somos. Portanto, quando novas políticas entram em vigor, novos procedimentos são exigidos, novos mandatos começam, novas equipes são criadas, novas visões são adotadas; se nós não nos percebemos como parte do processo de decisão, a transição pela qual cada um de nós passa pode ser mais longa e dolorosa.

Porém, nós somos todos profissionais. Sabemos que nossas organizações precisam de nós e não estão aqui para nos destruir. Sabemos que nossos chefes têm interesse em que sejamos capazes de alcançar nossos objetivos pelo motivo óbvio de que isso contribui para que eles alcancem os objetivos deles e para que nossa organização, o sucesso.

Deixe-me parar por aqui por alguns minutos e partir para o outro lado da equação, a questão da liderança. Eu intitulei esta palestra de "Liderando transições: a arte dos campeões". Então, quais são as questões de lideranças?

Na Escola de Serviço Público do Canadá, nós acreditamos que liderança não é só uma questão de hierarquia, isto é, posições de poder, embora esperamos que exista liderança na hierarquia de nossas organizações. É uma questão de sabedoria e responsabilidade e pode existir em qualquer nível de qualquer organização. Eu particularmente acredito que, no serviço público brasileiro e nesta organização, assim como no serviço público canadense, somos todos cobrados para exercitar nosso potencial de liderança, seja qual for o nível em que nos encontremos. Nós chamamos a isso de liderança orgânica.

As perguntas para cada um de nós, então, podem ser: "Será que estou preparado para ser responsável como líder, para fazer que mudanças boas e efetivas aconteçam em minha organização? Eu me importo com as transições que cada um de nós tem de atravessar para nos ajustarmos às mudanças ao nosso redor? Eu me importo com o lado humano da liderança?".

Liderança tem muitas definições, mas uma das que faz mais sentido para mim é a idéia de que ela é uma questão de influenciar os outros. Vocês, no seu trabalho diário, fazem isso o tempo todo, mas não estão sempre conscientes de sua influência. Então, eu acredito que é importante ficarmos mais conscientes dessa liderança. Nós precisamos reconhecer que realmente somos líderes e ver nossas ações desse ângulo.

Deixe-me contar para vocês algumas outras coisas sobre liderança em que acredito. Liderança está em cada esquina, rodeada por dilemas. E um dilema não é ter de escolher entre algo bom e algo ruim. É ter de escolher entre algo bom e algo bom, ou, mais difícil ainda, entre algo ruim e algo ruim. É uma questão de saber digitar com dez dedos e não só com dois, isto é, de saber usar todos os seus talentos. É uma 
questão de saber viver em ambigüidade. É uma questão de saber ser ambidestro. É uma questão de saber navegar em águas turbulentas. É uma questão de sucesso e de conquista. É uma questão de saber ganhar. É uma questão de saber ser realmente ético. É uma questão de saber crescer: crescer a si mesmo, ajudar os outros a crescerem e a se satisfazerem como seres humanos, ajudar a sua organização a crescer, a ficar mais efetiva, mais profissional e competente. É uma questão de saber ser campeão.

Liderança é uma questão de saber criar um ambiente de campeões, mas não o típico modelo de campeões em que há um vencedor e um perdedor; é uma questão de haver campeões que não só ganharam para si mesmos, mas deixaram lugar para os outros serem vencedores também.

Liderança é uma questão de verdade (a cabeça), mas não só de verdade, porque verdade sem compaixão é tirania, e liderança não é tirania!

Liderança é uma questão de compaixão (o coração), mas não só de compaixão, porque compaixão sem verdade é sentimentalismo, e liderança não é sentimentalismo.

Liderança é uma questão de tensão entre verdade e compaixão: o casamento da cabeça e do coração. Liderança é uma questão de sabedoria. E essa sabedoria pode e deve existir em suas comunidades, em suas organizações voluntárias, em seus planos de negócios, em suas organizações de serviço público e nesta instituição.

Na Escola de Serviço Público do Canadá, nós acreditamos que liderança tem quatro aspectos a serem dominados. O primeiro é o "eu". Nós chamamos esse aspecto domínio pessoal. Ele envolve quem você é, qual é a sua. Você está conectado com o seu sistema de valores? Em que você acredita? Como você se define como pessoa e por quê?

O segundo nível de domínio é o que chamamos de domínio interpessoal. Como você trabalha com outras pessoas? Como você tenta influenciar seus colegas, seus chefes, seus clientes, os cidadãos a quem você presta serviço?

O terceiro domínio envolve a organização em que você trabalha, o domínio organizacional. De que maneira você, como líder, contribui para o crescimento e desenvolvimento de sua organização? Como líder, de que maneira você ajuda sua organização a cumprir a missão dela?

O último tipo de domínio envolve o contexto no qual você existe, o mundo como um todo, a realidade da sua clientela... questões sociais, econômicas, políticas e de saúde pública no Brasil e no mundo. Chamamos a isso de domínio contextual.

Acredito que você tenha de tocar todos esses quatro domínios quando você reflete e tenta entender quem você é como líder. 
E assim nós chegamos às quatro questões principais de hoje. Quem, nesta sala e fora dela, é responsável por guiar você através do aspecto humano das mudanças, as transições pelas quais todos temos de passar? Quem tem de ajudar você a fazer um trabalho melhor nesse sentido? Quem é o responsável? Quem é? O presidente de sua organização? É o seu chefe? São vocês, as pessoas nesta sala? Em grande parte sim, porque tenho certeza de que vocês são peças-chave nesse quebra-cabeça.

As mudanças pelas quais suas organizações estão passando, as transições que tem de acontecer dentro de vocês e de seus colegas por causa dessas mudanças dependem de vocês. Vocês estão no comando das transições. Vocês são os campeões dessas transições.

É sua tarefa como líderes ajudar a si próprios e a outras pessoas a passarem por transições. Seu sucesso será proporcional ao quanto vocês põem em prática seu domínio pessoal, seu domínio interpessoal com seus colegas e clientes, seu domínio contextual para fazer de sua organização a melhor possível e seu domínio contextual no seu trabalho para os cidadãos do Brasil, a quem vocês prestam serviço.

Esse é o lado humano de "liderar transições", porque, para trazer suas qualidades de liderança para esse exercício, acredito que você tem de pôr quem você realmente é para trabalhar. Você tem de cuidar de você mesmo. Você tem suas próprias questões de transição para resolver. Você tem sua própria humanidade para cuidar. Você tem seu próprio eu interior para nutrir. Você pode dirigir-se aos seus mentores ou amigos para objetividade e apoio, mas você é responsável por você. Como líder, você tem de lidar com sua própria transição.

Em segundo lugar, você tem de ser um líder para as pessoas ao seu redor. Talvez um colega esteja tendo dificuldade com uma transição. Talvez essa pessoa precise que você a ouça mais, e saber ouvir é uma qualidade de liderança. Ouvir com atenção para entender requer tempo e energia de sua parte. E nem todo mundo vai estar na mesma página do livro, ao mesmo tempo. Nós fazemos nossa jornada por meio de nossas transições como indivíduos únicos, e o relógio pessoal é diferente para cada um de nós.

Acho que a maior parte das pessoas tem familiaridade com o modelo de curva de transição de Scott e Jaffe. Estou mostrando-o para vocês mais como lembrete. Se isso é novidade para alguns de vocês, eu os incentivo a refletir sobre esse modelo, quando estiverem pensando sobre suas próprias transições e sobre as de outras pessoas. O modelo diz simplesmente que geralmente nós começamos por uma fase de negação, quando nos defrontamos com a mudança. Nós falamos para nós mesmos: "Eles não estão falando sério. Eles vão mudar de idéia" ou "Não vai acontecer, porque eles vão ver que isso não vai funcionar" ou...? (preencha você esta lacuna). 
Geralmente nós passamos, então, para a fase de resistência. "Se eles acham que eu vou embarcar nessa, eles estão loucos" ou "Eles não sabem que o que eles estão jogando fora é o que faz esse lugar andar para frente. Eu vou continuar agindo daquele jeito".

Talvez, depois de um tempo, nós cheguemos à fase da exploração. É a fase do "Bem, vamos tentar..." É aqui que começamos a experimentar as idéias e a ter um pouco de sucesso.

Finalmente nós chegamos ao último nível, o compromisso, em que completamos nossa jornada de transição. Esperamos que essa jornada nos tenha levado a um lugar bom, a uma realidade confortável em que podemos começar a ser campeões de novo. Talvez essa experiência vai-nos ajudar quando a próxima mudança difícil aparecer em nosso caminho.

O que eu sugeri antes é verdade. Cada um de nós desloca-se pela curva de transição num ritmo diferente, e nós, os líderes, que estamos ajudando colegas a passar por uma transição, temos de conhecer esse fato e respeitá-lo.

Outra qualidade importante num líder é a capacidade de tornar mais fácil para os colegas as passagens por situações. Às vezes, tudo de que se precisa é uma pergunta simples, mas sincera, que permite ao outro que se abra. Isso põe você como um líder realmente disposto a ouvir o outro.

Uma outra qualidade é a capacidade de prever a direção em que você gostaria de ir com os outros e de se ver alcançando, com sucesso, essa direção. Em seu livro Os 7 hábitos das pessoas altamente eficazes, Stephen Covey fala em ver com os olhos da mente aquilo que você quer realizar. Ele chama isso de primeira criação, uma visualização do futuro. A segunda criação é tomar uma atitude concreta e realizar o trabalho.

Você pode achar que a visualização é algo que atletas profissionais fazem, o que é verdade. Mas eu conheço cirurgiões, advogados e policiais que também usam essa técnica. Eu me visualizo sendo bem-sucedido o tempo todo. Eu uso a visualização para me ajudar a atravessar as mudanças na minha vida profissional. Eu acho que você também deveria desenvolver a capacidade da visualização. Eu realmente acredito que isso melhora suas chances de sucesso.

Em seu livro $O$ desafio da liderança, James Kouzes e Barry Posner observaram milhares de gerentes bem-sucedidos e descobriram cinco "práticas-chave" que os gerentes de sucesso executam quando lidam com mudanças e transições:

1) Desafiar o processo - Seja lá qual for o processo, será que ele pode ser substituído por um melhor, que tem mais chances de dar certo?

2) Inspirar uma visão conjunta - Para onde vamos com essa mudança? Qual é nossa visão do futuro? Estamos fazendo o suficiente 
para comunicar nossa visão de maneira a permitir que as pessoas embarquem possuindo uma parte maior nas mudanças? Essa sensação de posse faz a transição ficar mais fácil.

3) Deixar os outros agirem - Como estamos na delegação de responsabilidade para outros? Colaboração e cooperação são parte de nossa cultura? Nós transmitimos poder para as pessoas durante os tempos de mudança?

4) Servir de modelo - Nossas ações realmente demonstram que nós acreditamos na visão?

5) Incentivando o coração - À medida que as pessoas começam a vencer a curva de transição, será que nós realmente as incentivamos a terem orgulho de ser quem são e de fazer o que fazem? As pessoas conversam sobre sua organização com orgulho?

Em seu artigo “O servo como líder”, Robert Greenleaf oferece comentários bastante perspicazes sobre a ética da liderança, sobre o "como" da liderança. Ele diz que trabalhar é ser servo primeiro, é realmente importar-se com o bem-estar das pessoas em nossa volta. "Daí uma escolha consciente nos faz aspirar a liderar." O líder-servo tem interesse em que as pessoas tornem-se "mais saudáveis, mais sábias, mais livres, mais autônomas". Se nós somos bem-sucedidos como líderes, ajudando os outros em suas jornadas de transição, queremos que eles realizem suas transições de forma a ficarem "mais saudáveis, mais sábios, mais autônomos". E não nos devemos esquecer de que esse é nosso objetivo também. Por causa de nossa própria jornada de transição, também precisamos ser "mais saudáveis, mais sábios, mais autônomos", à medida que nós atingimos novo nível de compromisso.

Em seu artigo, Greenleaf diz sobre mudança: “A gente não acorda todos os dias com vontade de reinventar a roda, mas, se a gente é servo, líder ou seguidor, está sempre procurando, ouvindo, na expectativa de que uma roda melhor para nossos tempos esteja a caminho". E complementa: "Pode ser que exista um sistema melhor do que aquele gente conhece. É difícil saber. Mas, seja lá o que for, se as pessoas que o lideram bem não estão presentes, um sistema melhor não produzirá uma sociedade melhor". Um sistema melhor não vai produzir um sistema público melhor ou uma instituição melhor, sem liderança.

Greenleaf, em seu artigo, comenta sobre a cura como função do líder-servo. Ele diz sobre a palavra "cura"... "tornar inteiro". Para os profissionais dessa instituição ou para aqueles que completam sua educação profissional aqui, "cura" também significa "manter pessoas inteiras". Ele diz: "Há algo sutil sendo comunicado para a pessoa que está sendo servida e liderada, se implícito, no pacto entre líder-servo e liderado, estiver o entendimento de que a procura pelo inteiro é algo que eles compartilham". 
Para que as pessoas se desloquem efetivamente através do lado humano das mudanças, que chamamos "transições", é preciso que os líderes sejam nossos campeões, e muitos líderes, tantos líderes quanto o número de pessoas nesta sala.

Saiba que você, o líder, deve também passar pela jornada de transição. Você não está imune a transições. Todos atravessam a curva de transição no seu próprio ritmo, alguns mais rápido, outros mais devagar.

Saibam que vocês têm de ser bons ouvintes uns dos outros, especialmente na primeira metade da curva de transição.

Na jornada de transição, nós temos de comunicar, comunicar, comunicar a história toda, e não segurar informação. Nós temos de compartilhar a visão.

Se nós não tivermos líderes que se importem em nos ajudar através de transições, a mudança não produzirá uma sociedade melhor, uma organização melhor.

Nós precisamos de líderes-servos que queiram ser "inteiros" conosco.

Adaptando uma frase de John Kotter, da Harvard University: Trabalhando com mudança em seu aspecto humano de transições é a essência do trabalho de liderança. As mudanças e as transições que as acompanham são um processo compartilhado que envolve toda a liderança de nossas organizações. Não é um processo coercivo, mas um processo colaborativo.

Passar por tudo isso com sucesso nos faz campeões.

Deixe-me encerrar contando uma lenda chinesa que enfatiza a importância da liderança. É a história de um discípulo do grande mestre Confúcio. Um dia o discípulo veio até Confúcio e perguntou:

- "Mestre, quais são as três coisas que uma nação tem de ter para ser forte?"

Confúcio pensou por um momento e disse:

- "Para uma nação ser forte, as três coisas necessárias são um exército poderoso, uma fonte abundante de comida e boa liderança".

O discípulo foi embora para pensar sobre a resposta. No dia seguinte ele voltou e disse:

- "Mestre, se uma nação pudesse ter somente duas coisas para ser forte, quais seriam elas?"

O grande mestre pensou e finalmente disse:

- "Se uma nação pudesse ter somente duas coisas, elas teriam de ser um suprimento abundante de comida e boa liderança".

O discípulo foi embora, mas voltou no dia seguinte e disse:

- "Mas, mestre, se uma nação pudesse escolher somente uma coisa para fazê-la grande, qual seria?" 
Confúcio pensou por bastante tempo. Finalmente ele disse:

- "Essa é difícil para decidir. Veja bem, sem fonte abundante de comida, o povo de uma nação não sobrevive; mas, sem boa liderança, eles não têm nenhuma razão para viver."

Liderança para ajudar a nós mesmos e ao outros durante transições na vida não é a única coisa de que precisamos, mas, com certeza, é uma das duas coisas mais importantes. E, para mim, a liderança que nos ajuda a atravessar nossas transições é a arte dos campeões. 

Nacional de Administração Pública, voltada para a divulgação e debate de temas relacionados ao Estado, à administração pública e à gestão governamental. Procurando o aprimoramento permanente da revista, tanto no seu conteúdo quanto na apresentação gráfica, pedimos aos nossos colaboradores a observação das normas abaixo descritas.

\section{Normas para os colaboradores}

1. Artigos: sempre inéditos no Brasil, deverão ter até 25 laudas com 20 linhas de 70 caracteres, acompanhados de um resumo analítico do artigo em português, espanhol e inglês, de cerca de 150 palavras, que permita uma visão global e antecipada do assunto tratado, e de 3 palavras-chaves (descritores) em português, espanhol e inglês que identifiquem o seu conteúdo. Tabelas, quadros e gráficos, bem como notas, devem limitar-se a ilustrar conteúdo substantivo do texto. Notas devem ser devidamente numeradas e constar no final do trabalho e não no pé da página. Referências de autores no corpo do texto deverão seguir a forma (AUTOR, data). Referências bibliográficas devem ser listadas ao final do trabalho, em ordem alfabética, e observar as normas da ABNT. Exemplos:

\section{Referências no corpo do texto}

(ABRUCIO, 1998)

\section{Referências bibliográficas}

Livro

CASTRO, José. Direito municipal positivo. Belo Horizonte: Del Rey, 1999.

\section{Artigo em coletânea}

GONDIM, Linda. Os 'Governos das Mudanças' (1987-1994). In: SOUZA, Simone (org.), Uma nova história do Ceará. Fortaleza: Edições Demócrito Rocha, 2000.

\section{Artigo em periódico}

BOVO, José. Gastos sociais dos municípios e desequilíbrio financeiro. Revista de Administração Pública, Rio de Janeiro, 35(1), p. 93-117, jan/fev, 2001.

\section{Monografia, dissertação ou tese acadêmica}

COMASSETTO, Vilmar. Conselhos municipais e democracia participativa sob o contexto do desenvolvimento sustentável na percepção dos prefeitos municipais. Dissertação de Mestrado. Programa de Pós-Graduação em Engenharia de Produção. Florianópolis: Universidade Federal de Santa Catarina, 2000.

2. Ensaios: sempre inéditos no Brasil, deverão ter até 10 laudas com 20 linhas de 70 caracteres.

3. Vinculação institucional: Artigos e ensaios devem vir acompanhados de uma breve informação sobre a formação, vinculação institucional do autor (em até duas linhas) e email para contato.

4. Avaliação: a publicação dos textos está sujeita à avaliação, por sistema de "blind review" de 2 a 3 pareceristas, os quais se reservam o direito de sugerir ao autor modificações que atendam aos objetivos da revista.

5. Encaminhamento: Os originais de todos os trabalhos devem ser encaminhados em arquivo digital, em formato de uso universal (.doc, .rtf ou .txt) e enviados para editora@enap.gov.br. Os originais enviados à ENAP não serão devolvidos. A ENAP compromete-se a informar os autores sobre a publicação ou não de seus trabalhos.

Para maiores informações acesse www.enap.gov.br

ENAP Escola Nacional de Administração Pública

Diretoria de Comunicação e Pesquisa

SAIS Área 2-A Brasília, DF - CEP 70610-900

Tel: (61) 4457102 - Fax: (61) 4457178

E-mail: editora@enap.gov.br 